\title{
Teaching Information Literacy Skills to Senior Undergraduate Engineering Students
}

\author{
Jennifer Cong Yan Zhao \\ Schulich Library of Science and Engineering \\ McGill University, Montréal, Québec, Canada \\ jennifer.zhao@mcgill.ca
}

\author{
Michael Rabbat \\ Electrical and Computer Engineering \\ McGill University, Montréal, Québec, Canada \\ michael.rabbat@mcgill.ca
}

\begin{abstract}
Information Literacy Standards for Science and Engineering/Technology establish a set of abilities for students to recognize their information needs, access information effectively and efficiently, evaluate information critically, and use information in a legal and ethical way. The Standards aim to help students accomplish academic goals in their studies and build lifelong learning skills, and they are also well-aligned with the CEAB graduate attributes. Moreover, it is important that students acquire these skills before completing their undergraduate degrees since, upon entering the workforce, they will need to investigate problems and communicate complex ideas with colleagues and clients in both written and oral format, and they will not have the same support available as when they are in university.

The authors, an engineering librarian and instructor, collaborated in the Fall 2012 semester to offer two information literacy training sessions within a final-year electrical and computer engineering course. This paper presents the topics and pedagogies used in this training and discusses the challenges that the authors encountered. Recommendations on integrating information literacy training into engineering curriculum are also provided.
\end{abstract}

Keywords: engineering education, information literacy, CEAB graduate attributes, library instruction

\section{INTRODUCTION}

The Canadian Engineering Accreditation Board (CEAB) criteria identify 12 attributes that students graduated with accrediting engineering degrees should possess [1]. Among the 12 attributes are investigation, communication skills, and lifelong learning.

The Association of College \& Research Libraries (ACRL) Information Literacy (IL) Standards for Science and Engineering/Technology [2] aim for science and engineering students to be able to:
- "determine the nature and extent of the information needed;

- acquire needed information effectively and efficiently;

- $\quad$ evaluate the procured information and its sources, and as a result, decides whether or not to modify the initial query and/or seek additional sources and whether to develop a new research process;

- $\quad$ understand the economic, ethical, legal, and social issues surrounding the use of information and its technologies and either as an individual or as a member of a group, uses information effectively, ethically, and legally to accomplish a specific purpose; and

- $\quad$ understand that information literacy is an ongoing process and an important component of lifelong learning and recognizes the need to keep current regarding new developments in his or her field."

Both the CEAB attributes and the IL standards prescribe abilities that engineering undergraduates should obtain during their higher education. These should be taken into account when designing curricula and they can also be used as guidelines for assessing learning outcomes.

IL skills create the base for students to develop CEAB attributes. Dervin's work [3] on human information needs provides a "typology of scenarios" in which information is useful. They are (1) making decisions, (2) solving problems, (3) handling concerns, and (4) gaining comprehension. These four scenarios arise while conducting an engineering project involving any of the $12 \mathrm{CEAB}$ graduate attributes. Murphy and Saleh [4] note that IL is a "hidden attribute woven through" all the CEAB's attributes. Nelson and Fosmire [5] emphasize the connection between IL and the design, communication, and lifelong learning. Given the relevance of the IL standards and CEAB attributes, engineering instructors and librarians should work together to come up with a 
platform to equip students with these skills through a shared teaching and learning agenda.

One promising platform is a research project that engineering instructors assign to their students. Mills and Treagust [6] review the effectiveness of applying project-based and problem-based learning to engineering education in different engineering programs and universities, and propose that projectbased learning should be adopted as a key component in the later years of engineering programs. By completing a research-intensive project, students can gain learning motivation, exposure to industry practices, as well as the qualities defined by accreditation criteria. Ten years after Mills and Treaguest's proposal, many engineering faculty have adopted this pedagogy: having students write a research project report or paper, especially for students in their last year of university studies [7].

The sequence of the five standards of IL perfectly reflects a research process - defining information needs, finding information, evaluating information, and using information to accomplish the goal in the context that takes legal, ethical, and social-economic issues into consideration. Since the CEAB attributes and IL skills can be developed via such a research experience [7], the best way to teach students these competencies is to work on a research project assignment designed jointly by engineering instructors and librarians.

The authors, an engineering librarian and instructor, collaborated in the Fall 2012 semester to offer two information literacy training sessions within a fourthyear electrical and computer engineering course. The sessions focused on information literacy skills needed to accomplish the project paper assigned by the instructor and to support lifelong learning. This paper presents the topics and pedagogies used in this training and discusses the challenges that the authors encountered. Recommendations for integrating information literacy training into engineering curriculum are provided as well.

\section{APPROACH}

\subsection{Learning Outcomes}

At the outset of their collaboration, the authors determined the following learning outcomes for these two IL sessions.

- After Session One, students will be familiar with the information sources and types of material in the field of Electrical, computer and software Engineering, and be able to find appropriate sources for their research topic.
- After Session One, students will be able to establish efficient search strategies for a selected information source and to determine the most efficient way to retrieve the full text.

- After Session One, students will be able to evaluate the information that they find and select proper information for their work.

- After Session Two, students will have a deeper understanding of academic integrity and will be aware of ways to avoid plagiarism.

- After Session Two, students will become familiar with principles of proper citation in scholarly works and be able to cite properly with the aid of citation management software.

\subsection{Determining the Learning Outcomes}

It is not always easy to figure out what exactly students should learn from an IL session. McGill University Libraries have successfully embedded one library session into another engineering course called Communications in Engineering. This one and a half hour session teaches students in all engineering disciplines techniques for finding an appropriate database according to library guides, searching for a topic in it, and handling references using EndNote, the citation management software licensed by McGill Libraries. This session helps students in accomplishing their course assignment - a research paper on a given engineering topic with citing requirements of scholarly sources. However, one session is not enough for students attain the whole set of IL competencies defined by the ACRL IL standards.

There is agreement in the literature that, while students may have the opportunity to learn about certain IL skills from one generic training session, they often need help to apply generic skills to their own discipline [7, 8]. Having extra subject-focused IL training, beyond the generic session, is indispensable for developing an information literate graduate. Embedding IL content within advanced undergraduate courses is particularly important since these students already have acquired domain-specific knowledge, and this is the last chance for students to obtain IL skills before they graduate.

The authors of this paper identified the following topics that needed to be addressed in the two sessions.

2.2.1 Searching for Information Sources. Every discipline is unique in its information source framework. It is essential to give students such a framework so that they can organize the sources that they encounter in a way that makes them useful for solving subject-specific problems. Mcalpine [9] states 
that "advanced organizers, explicit frameworks, are often suggested as a way of helping students foreshadow the new learning and make links" to their existing knowledge base. This is useful for both accomplishing their coursework and fulfilling their information related tasks at a workplace. Although students can use a library guide to locate the relevant databases to accomplish their studies, additional sources are frequently used, and they require different search strategies for maximum efficacy.

Search engines such as Google and Google Scholar make it easy to locate relevant material. This might give students a misunderstanding that the Internet is the only source for their information needs and that academic databases are unnecessary. It is important for them to learn what they can find on the Internet, when they need to rely on the library's collection, and how to efficiently use various available sources. This is of significance for both completing their program studies and pursuing their career development after graduation.

Finally, when content is found using Internet search engines, undergraduate students often do not know how to determine whether the source they are using is from a scholarly conference or journal, whether it has been peer-reviewed, or how to identify the relevant citation information. This causes difficulty when retrieving the full text and when citing the source as will be discussed below.

2.2.2 Evaluating Information. A generic library session tells students that peer-reviewed articles are the most reliable sources. However, due to the rapid development of technology in electrical, computer, and software engineering and the publishing lag of a peerreviewed journal article, the only source that is available when students or engineers start investigating a particular solution is often technical reports and documentation produced by companies and often via the public Internet. This makes it difficult to assess the quality and authority of a source, and students do not always understand the difference between a companygenerated report and a peer-reviewed technical article. They may assess the reliability of the sources found by comparing different sources for consistency. However, they are generally less capable of determining the quality of information and of labeling a source, e.g., as peer-reviewed versus popular press or grey literature.

2.2.3 Citing Information. The CEAB description for the communication attribute states that an engineering graduate should have "the ability to communicate complex engineering concepts within the profession and with society at large. Such ability includes reading, writing, speaking and listening, and the ability to comprehend and write effective reports and design documentation." [1]. Citing other authors' ideas in order to build on the knowledge base and support an argument or solution in a paper is critically important. Unfortunately, students commonly have problems with properly citing sources. A very common error is to cite a document by using only the URL or including the URL in lieu of key citation information such as the publication title or conference title and dates. This is not so surprising since students of this generation are accustomed to gathering and producing information, such as blog posts or tweets, primarily for immediate consumption. It is important that students be taught and reminded that references should be appropriately cited and a permanent link should be given to an online source, so that readers can trace the cited articles at any time in the future.

Although the incorrect formatting of citations could result from overlooking citation requirements or being reliant on citation management software, it could also be caused by the unawareness of plagiarism [11]. Information Literacy training should be integrated into the engineering curriculum to help students better understand the issue of plagiarism and to deal with referencing [12]. This skill will not only help them accomplish their university studies; it will also help them to write reports and papers after they enter into their engineering careers.

\subsection{Instructional Activities.}

These two information literacy sessions were largely taught in the lecture form for the following reasons. First, most students in this course were in the last year of their program. They had already been exposed to search principles and techniques from the generic library session in the Communication in Engineering course. A hands-on workshop on searching a database was not necessary. Second, we felt the lecture format would be more efficient to go through the topics that we had designed for this course. Third, a typical research-based instruction model should include "engagement", "informing", "practice", and "summative assessment" [9], and practice takes the major importance. Given these two sessions were aimed to help the students accomplish a research project required for this course, the students would have to "practice" the research outside of the class.

In the first session, the librarian used an example topic that was selected with the help of the course instructor. She demonstrated searching in one subject specific database, one citation database, and Google Scholar. The difference of the results in each source was illustrated, and the reasons for these differences 
were explained. By doing this, the students gained a deeper understanding of these sources and would be better capable of using them depending on their specific needs. Some specialized functions of different sources were introduced, including using index terms in the subject-specific database, setting up email alerts and RSS feeds in a citation databases to keep track of the development of a topic, using the Cited by and Related Articles features to optimize searching in Google Scholar, and using Google Scholar to import a citation into the citation management software. A set of criteria and examples for evaluating information were given, with an emphasis on evaluating web information.

The second session focused on scholarly citation and plagiarism. McGill University's statement on academic integrity and plagiarism was explained, and a few tricky scenarios were discussed. Guidelines for when a reference should be cited were provided and the rationale for scholarly citation was explained. Finally, the IEEE citation style was instructed and examples for common materials were explained.

Outside of these two in-class sessions, the librarian also provided office hours and individual consultations to support the students to practice their search, evaluation, and citation skills. This aligns with the emphasized practice phase in Mcalphine's "researchbased instructional model" [9].

\subsection{Assessing Expected Learning Outcomes}

Learning results need to be measured so that the learning outcomes and instructional activities can be adjusted accordingly. Harris [13] promotes the concept of "outcome-based assessment". He states that "the new CEAB, entitled 'graduate attributes,' is focused on outcomes: students' ability to demonstrate the knowledge and skills they have learned. In other words, outcomes assessment identifies what students have learned as compared to what they have been taught."

The assessment for these two sessions was based on students' papers, including the quality of the sources that students cited, the correctness of in-text citations, and the reference list, as suggested in [14]. Although the feedback was positive, a direct survey with students would better affirm this collaborative approach to teaching IL skills. In the future, a questionnaire aimed for understanding students' IL needs will be sent out before the session. Another assessment, to find out how well students obtain the knowledge and skills taught in the session, will follow after students finish the paper, and it should collect both quantitative and qualitative data.

\section{DISCUSSION}

\subsection{Why Two Sessions Are Better Than One}

This collaborative information literacy training was given in two one-hour sessions, which differed from the usual one-shot course-related library session model. Gaining information literacy is a process and this process aligns with the research process. Instead of delivering all the content in a one-shot session, the authors preferred to separate them into two parts and offer them to students at the appropriate stage in the course project. The instructor wanted the students to start searching for articles on their topic early in the semester, to have time to digest and analyze the material while working on their own project solution. Writing the report occurred later in the semester. So these two information literacy sessions were given at particularly selected times, one in the end of September and one in early November. By this design, the effectiveness of each session could be maximized in terms of the time and learners' needs. Another advantage of this arrangement was to avoid overloading students with information.

\subsection{Make It Relevant}

Shenton and Fitzgibbons [16] state that "information literacy instruction can be made more effective if learners' inherent behaviors, motivations and preferences are taken into account." They also discuss the following three solutions: 1) selecting topics for assignments; 2) demonstrating the role of information literacy skills related to their studies and lives; and 3) instructors collaborating with learners.

The authors of this article selected topics closely relevant to the course content and students in this final year of this program. Saunders in her 2012 paper [17] stated that "the seeming unwillingness of faculty to partner with librarians may have more to do with a lack of understanding of how librarian can contribute to and support their instruction." This collaborative selection process by librarians and instructors created an opportunity for librarians and faculty to understand each field better. Also, it is indispensable in order to make the session relevant.

Before the IL sessions, the instructor emphasized to the class the importance and relevance of IL. This helped motivate students and allowed them to think about questions and issues before each session. This generated inquiry-based learning. However, a pre-class survey would be helpful to identify students' particular IL needs and to serve as an advertisement to develop students' interest in attending the sessions. 


\subsection{Thoughts on Information Literacy Embedding Models}

Given McGill Libraries' current practice of providing a generic library session to all engineering students, additional subject-orientated information literacy session is recommended. It should be done collaboratively by subject librarians and course instructors in order to make it specific for students in a particular discipline and relevant to their IL levels.

Also, due to the fact that developing information literacy skills closely aligns with a research process, it is best to embed such a subject-focused session into a disciplinary course which requires students to finish a research paper or report. Based on topics that are identified by the librarian and instructor, more than one session is recommended. The time to deliver these sessions should also align with students' project progress.

A systematic review of the third and fourth years' disciplinary courses is recommended; through this exercise, appropriate courses can be identified for integration with IL skills. The efficiency of training can be ensured, and the time of both instructors and students can be respected.

\subsection{Building Collaboration between Librarians and Faculty Instructors}

Faculty members need to be reminded that information literacy covers much more than library instruction. Faculty members often believe they have embedded IL content into the curriculum via exercises such as "completing information exercise", "research methods course", " "core skills' training modules", "computer skills classes" [10]. However, information literacy goes well beyond these skills; it is composed of a set of competencies that enable an information literate engineering graduate to deal with information, including recognizing information needs, finding information efficiently, selecting reliable information, and putting information together legally and ethically for accomplishing a purpose.

In McGuinness' 2006 study [10] about faculty's thoughts on having collaborative information literacy training in their class, he stated that "the extent to which students develop as information literate individuals depends almost entirely on personal interest, individual motivation and innate ability, rather than on the quality and format of the available instructional opportunities." Some participants even thought that students could build these skills by themselves eventually, i.e. "learning by doing" [18]. This is debatable. If an individual always relies on others to find, analyze and summarize information for him, he will never learn how to do it on his own. This is also risky in that curriculum outcomes and the CEAB graduate attributes may be realized if students do not acquire these skills by graduation.

Once faculty become familiar with the definition and standards of IL, they are much more likely to incorporate information literacy concepts and components into their teaching, and to assess information literacy competencies as well [17]. This calls on librarians to initiate and market information literacy to faculty.

Although librarians' individual contacts with engineering faculty are essential to make the collaboration happen, this connection is not sustainable as librarians and instructors may leave their jobs and librarians' subjects and instructors' courses may change over the time $[7,8]$. It is recommended to establish a formal partnership at the unit level.

Also, it is important to be flexible with the session time. Faculty are often concerned that their curriculum is too dense to incorporate an extra IL session even if they agree that IL is important. The IL session could be embedded into a disciplinary class during lecture time or lab hours, as well as offered as a standalone session after class. In terms of student attendance, the lecture time is the best. However, this may not be most effective. Since students who come to standalone sessions are those who decide to come and often have questions, the learning outcome is often better as students may actively take more away from the training. Flexibility with the session time could ensure that students who need information literacy skills get the chance to learn.

\section{CONCLUSION}

Integrating information literacy training into undergraduate engineering education should result in strengthened graduate attributes. Systematically embedding this training into engineering courses based on a mapping of course outcomes can ensure an efficient experience for both students and educators.

Librarians and instructors should work together to identify the best way to embed information literacy training into disciplinary curricula. Instructors should consider how to redesign the curriculum in order to incorporate information literacy learning. Librarians need to think beyond individual instructional activities. More thoughts should be put into how to create the integrating practice, how to promote information literacy to both faculty and students, as well as how to make the training relevant and meaningful. 


\section{References}

[1] Engineers Canada, 2012 Canadian Engineering Accreditation Board Accreditation Criteria and Procedures. Available as of March 30, 2013 from http://www.engineerscanada.ca/files/w_Accreditation_Cr iteria Procedures 2012.pdf

[2] The ALA/ACRL/STS Task Force on Information Literacy for Science and Technology, Information Literacy Standards for Science and Engineering/Technology. Available as of March 30, 2013 from http://www.ala.org/acrl/standards/infolitscitech

[3] Brenda Dervin, "Strategies for dealing with human information needs: Information or communication?" Journal of Broadcasting \& Electronic Media, vol. 20, no.3, pp. 323-333, 1976.

[4] Sharon Murphy and Nasser Saleh, "Information literacy in CEAB's accreditation criteria: the hidden attribute," in Proceedings of The Sixth International Conference on Innovation and Practices in Engineering Design and Engineering Education, (Hamilton, ON; July 27-29, 2009).

[5] Megan Sapp Nelson and Michael Fosmire, "Engineering librarian participation in technology curricular redesign: Lifelong learning, information literacy, and ABET criterion 3," in ASEE Annual Conference Proc., 2010.

[6] Julie E. Mills and David F. Treagust, "Engineering education - is problem-based or project-based learning the answer?" Australasian Journal of Engineering Education, vol. 3, pp. 2-16, 2003.

[7] Fiona A. Salisbury, Sharon Karasmanis, Tracy Robertson, Jenny Corbin, Heather Hulett and Tai L. Peseta, "Transforming information literacy conversations to enhance student learning: New curriculum dialogues," Journal of University Teaching \& Learning Practice, vol. 9, no. 3, 2012.

[8] Gloria J. Leckie and Anne Fullerton, "Information literacy in science and engineering undergraduate education: Faculty attitudes and pedagogical practices," College \& Research Libraries, vol. 60, no. 1, pp. 9-29, 1999.

[9] Lynn Mcalpine, "Designing learning as well as teaching A research-based model for instruction that emphasizes learner practice," Active Learning in Higher Education, vol. 5, no. 2, pp. 119-134, 2004.

[10] Claire McGuinness, "What faculty think - exploring the barriers to information literacy development in undergraduate education," Journal of Academic Librarianship, vol. 32, no.6, pp. 573-582, 2006.

[11] Donald D. Carpenter1, Trevor S. Harding, Cynthia J. Finelli, Susan M. Montgomery, Honor J. Passow, "Engineering students' perceptions of and attitudes towards cheating," Journal of Engineering Education, vol. 95, no. 3, pp. 181-194, 2006.

[12] Suzanne Keilson and Susan Cooperstein, "Work in progress - information literacy, plagiarism and engineering education," in Frontiers in Education Conference-Global Engineering: Knowledge Without Borders, Opportunities Without Passports, 2007. FIE'07. 37th Annual, pp. T3B-15-16, 2007.

[13] Jessica Harris, Alan Steele, Donald Russell, "Progress on defining the CEAB graduate attributes at Carleton University," in Proc. of the Canadian Engineering Education Association, 2011.

[14] Patricia A. Iannuzzi, "We are teaching, but are they learning: Accountability, productivity, and assessment," Journal of Academic Librarianship, vol. 25, no.4, pp. 304-305, 1999.

[15] Joan.R. Kaplowitz, Transforming information literacy instruction using learner-centered teaching. London: Facet Publishing, 2012, 254 pp.

[16] Andrew K. Shenton and Megan Fitzgibbons, "Making information literacy relevant," Library Review, vol. 59, no.3, pp. 165-174, 2010.

[17] Laura Saunders, "Faculty perspectives on information literacy as a student learning outcome," Journal of Academic Librarianship, vol. 38, no.4, pp. 226-236, 2012.

[18] Pauline Ford and K. Hibberd, "Creating effective and engaging information literacy programmes for the dental curriculum," European Journal of Dental Education, vol. 16, no.1, pp. e41-e46, 2012.

CEEA13; Paper 041

Montreal, QC; June 17-20, 2013 